\title{
ELEMENTOS DE ARTICULACIÓN TEÓRICA PARA EL SUBALTERNISMO LATINOAMERICANO. CANDIDO Y BORGES
}

POR

Alberto Moreiras

Duke University

\section{Autoarqueología del subalternismo}

Estudiando la sociedad esclavista brasileña, Roberto Schwarz insiste en que el desplazamiento de ideas causado por el esclavismo produjo un envilecimiento "de la vida ideológica y [así] disminuyó las posibilidades de pensamiento genuino [reflexão]" (Schwarz, "Idéias" 22). ${ }^{1}$ La formulación de Schwarz es particularmente inquietante para los estudiosos de sociedades periféricas o semiperiféricas, puesto que aceptar que las perturbaciones ideológicas disminuyen las oportunidades sociales para la "reflexão" parece implicar que una ideología no corrompida las aumenta. Si tal es el caso, el pensamiento genuino, que en el caso de Schwarz refiere a la posibilidad de una conciencia situacional atenta a las contradicciones sociales y reflexiva con respecto de su propia implicación en ellas, sería más susceptible de darse en el centro hegemónico, donde la saturación ideológica es más intensa y, por decirlo así, más pura y falta de espejismos doblemente engañosos. Alguna contradicción dialéctica está funcionando en esto - la misma quizá que está también presente en el ensayo de Fredric Jameson "Third World Literature in the Era of Multinational Capitalism", y que de hecho forma su mismo suelo: la "verdad" de los textos metropolitanos se revelaría según Jameson en los textos "tercermundistas", pero sólo porque los textos tercermundistas son incapaces de abandonar "la relación objetiva entre política y dinámica libidinal" (80), y son por lo tanto deficientes en sólo ese sentido. Paralelamente, en Schwarz, la falta de oportunidades para el pensamiento genuino habría constituido el caldo de cultivo para el gran deslumbramiento de Machado de Assis. ${ }^{2}$

\footnotetext{
1 "Conhecer o Brasil era saber destes deslocamentos, vividos e praticados por todos como uma espécie de fatalidade, para os quais, entretanto, não havia nome, pois a utilização imprópria dos nomes era a sua natureza. Largamente sentido como defeito, bem conhecido mas pouco pensado, este sistema de impropriedades decerto rebaixaba o cotidiano da vida ideolóxica e diminuía as chances de reflexão" ("Idéias" 22). Traduzco "reflexão" como "pensamiento genuino" siguiendo la solución optada en la traducción inglesa ("Misplaced" 28).

2 "As idéias fora do lugar" es el primer capítulo de los dos volúmenes consagrados por Schwarz al novelista decimonónico, Ao vencedor as batatas y Un mestre na periferia do capitalismo. Machado de Assis.
} 
La reversión dialéctica en Jameson o Schwarz consiste en mantener que tales deficiencias en la periferia del capitalismo son en el fondo una suerte de privilegio epistemológico - el privilegio que ya la dialéctica hegeliana nos enseñó a apreciar en la posición del esclavo, "único que sabe lo que realmente son la realidad y la resistencia de la materia" (Jameson, "Third" 85). ${ }^{3}$ La imposibilidad de abandonar la relación objetiva entre política y dinámica libidinal, definida como la situación propia de comunidades de experiencia y conocimiento subalternos, lejos de constituir una limitación, es más bien el fundamento de un privilegio epistemológico. Desde el punto de vista del estudioso de la cultura subalterna (voy a entender aquí esa expresión en un sentido meramente relacional, esto es, como cultura no-dominante), es sin embargo un privilegio que no se presenta como tal sin extraordinarias complicaciones.

La singularidad cultural es el campo utópico del subalternista. El subalternista debe a la vez afirmar, y subsecuentemente encontrar y re-presentar (es decir, precisamente no "construir"), singularidad cultural, entendida como diferencia con respecto de la formación cultural dominante. Al mismo tiempo, el subalternista debe también abandonar la noción misma de singularidad cultural a partir del momento en que debe reconocerla como simple variante en la relación objetiva entre política y dinámica libidinal. Sin tal abandono, el subalternista no podría establecer su vindicación de conocimiento materialista, esto es, noideológico, y quedaría como pasto de acusaciones de culturalismo idealista.

El "Founding Statement" del Grupo de Estudios Subalternos Latinoamericanos nos ofrece un ejemplo de tal dificultad en su apelación doble y contradictoria, por un lado, a un sujeto necesariamente espectral, sin positividad, que sólo puede aparecer en "dicotomías estructurales, fisuras" ("Founding" 136), que sólo puede hablar en "espacio[s] en blanco" (144), pero que es también, bastante misteriosamente, conocible en o a través de la "“experiencia vivida"“ (140). "Experiencia vivida" mienta la singularidad e inmediatez irrepresentable, esto es, una positividad necesariamente irrepresentable aunque accesible en el sujeto subalterno, mientras que la afirmada negatividad del sujeto subalterno mienta la incapacidad del subalternista de representar sin contradicción (o incluso la incapacidad de autorrepresentación por parte del sujeto subalterno mismo).

Esta dificultad fundacional en el trabajo del subalternista no es necesariamente una limitación ni una deficiencia. Al contrario, es la base de su posibilidad misma de constituir conocimiento. Dado que la contribución de estudios subalternos en sus dimensiones tanto políticas como epistemológicas depende a mi juicio de esa problemática constitutiva, un examen crítico riguroso de sus parámetros y paradojas se hace particularmente necesario. Otra forma de decir lo mismo es postular que los estudios subalternos no deben simplemente comprometerse en el análisis arqueológico y en la reconstrucción de conocimientos silenciados, sino que, simultáneamente, deben también embarcarse en lo que podríamos llamar una autoarqueología, sin la que permanecerían ciegos a sus propias condiciones de enunciación, y así por lo tanto, en última instancia, ciegos a su propia singularidad cultural.

\footnotetext{
${ }^{3}$ Jameson refiere también, por cierto, a Gyorgy Lukács en Historia y conciencia de clase, y a su teoría de que los dominados están en mejor posición que los dominantes para entender la totalidad social ("Third" 87-88).
} 
El presente ensayo parte de la presuposición de que el subalternismo es un nuevo paradigma para estudios culturales latinoamericanos, y de que no se puede en última instancia estar en desacuerdo con él. Es más, que el desacuerdo sólo será productivo desde el fondo de un acuerdo más profundo. Las razones de tal hecho son históricas más que teóricas, en la medida en que es la historia contemporánea la que ha hecho anticuados o insuficientes los paradigmas previos de interpretación cultural. ${ }^{4}$

Dos recientes volúmenes de ensayos, los editados por Hermann Herlinghaus y Monika Walter, y por John Beverley, José Oviedo y Michael Aronna respectivamente, han abierto una segunda fase en el debate sobre la posmodernidad latinoamericana y sus formas culturales, en la medida en que han agotado las posibilidades definitorias de la primera. Lo que ahora parece importante es entender las consecuencias prácticas de las definiciones previas para el trabajo intelectual y el trabajo político. Los textos canónicos de la modernidad latinoamericana deben releerse y reinterpretarse buscando la manera en que el entendimiento de posicionalidad histórica en ellos hallable sirva para iluminar, y no para oscurecer, la nuestra. Supuesto que el subalternismo haya aparecido, en los trabajos de los teóricos más influyentes, como el horizonte inescapable del latinoamericanismo crítico en tiempos de globalización tardo-capitalista, la tradición de pensamiento latinoamericano pervive como cifra genealógica de una historia de la que no se puede simplemente abjurar, sino que debe afirmarse activamente, incluso en el mismo momento en que uno toma distancia histórica con respecto de ella. Puesto que la distancia histórica, cuando se representa como distancia, no es nunca simplemente histórica.

La pregunta es pues cómo entender tanto la continuidad como la discontinuidad entre las empresas de crítica cultural definidas por los "maestros/as pensadores/as" del pasado reciente y su redefinición o rearticulación en el subalternismo latinoamericano. ¿Debe entenderse el subalternismo como una ruptura radical respecto de la tradición en cualquier configuración disciplinaria de conocimiento en que se manifieste? Al mismo tiempo que afirmo que el subalternismo es un modelo nuevo para la interpretación o reinterpretación de las culturas latinoamericanas, todavía concibo el movimiento subalternista, no como una ruptura radical con respecto de previos modos disciplinarios, sino más bien como expansión de bordes disciplinarios, ya vivamos en ellos desde perspectivas posthistóricas, postantropológicas, postliterarias o posteóricas.

Las siguientes páginas se ocuparán de realizar dos calas de interés e intención autoarqueológica a partir de la obra de dos improbables precursores del subalternismo, el crítico brasileño Antonio Candido y el escritor argentino Jorge Luis Borges. No hay en esta opción voluntad alguna de provocación, sino más bien, simplemente, por un lado la constatación de que en "Literatura y subdesarrollo" y en "La lotería en Babilonia" se dan

\footnotetext{
${ }^{4}$ Hay una presuposición siempre necesariamente orientalista en el subalternismo, como lo hay en toda empresa que busca legitimidad en el estudio de la alteridad humana. La crítica del orientalismo subalternista ya ha sido, sin embargo, hecha por Gareth Williams para el caso latinoamericanista, desde una posición de simpatía crítica, en dos ensayos con los que estoy en completo acuerdo y a los que remito: "Fantasies" y "After Testimonio". Mi uso del término sin duda incómodo "subalternismo" en preferencia a "estudios subalternos" apunta a los obvios riesgos intelectuales implicados en la empresa -que sin embargo no son centralmente el tema de este trabajo.
} 
dos formas anticipativas de pensar la crisis del estado nacional-popular latinoamericano, y por otro lado la intuición de que es la ruptura histórica del estado nacional-popular la que opera el profundo surco definitorio de nuestra situación actual.

No tengo por lo tanto intención de reivindicar a ninguna de las dos figuras como protosubalternistas - al contrario, mi interés es encontrar en su obra vínculos no triviales entre el pasado y el presente del pensamiento latinoamericano. El subalternismo no es sino la más coherente de las respuestas hasta ahora encontradas a la configuración estatal neoliberal que es, en apariencia al menos, la sucesora histórica del estado fordistakeynesiano que aceleró su muerte en América Latina desde la crisis de la deuda pública de 1982. Para que esa coherencia adquiera suficiente profundidad histórico-crítica es necesario probarla en la confrontación con modelos alternativos de pensamiento en el momento álgido de su legitimidad — supuesto que tales modelos guarden también alguna posibilidad de apelación al "pensar genuino" que menciona Schwarz. ${ }^{5}$

\section{Del nativismo de país nuevo a los estudios subalternos}

"La dependencia cultural", dice Antonio Candido, es "un hecho considerado natural" (342). Escribe en 1970 tratando de entender lo que entonces consideraba "la fase presente" de la experiencia cultural en Latinoamérica, que él llamaba "la conciencia del subdesarrollo" (347). Para Candido, la conciencia del subdesarrollo es la tercera de las tres categorías básicas que resumen la evolución de la cultura literaria moderna en el subhemisferio. La primera es el "nativismo de país nuevo," y corresponde a un periodo de tiempo caracterizado por una fe eufórica en las potencialidades desarrollistas de la región. La segunda es la "preconciencia del subdesarrollo," y comienza a hacerse visible en los años treinta, cuando

[la literatura] abandona su amenidad y su curiosidad, presintiendo o percibiendo lo que había de enmascaramiento en el encantamiento pintoresco o en la caballerosidad ornamental con que antes se trataba al hombre rústico. No es falso decir que la novela adquirió, desde este punto de vista, una fuerza demitificadora que se anticipa a la toma de conciencia de los economistas y políticos. (337)

Después de la Segunda guerra mundial adviene "una conciencia catastrófica de retraso" (337), "pesimista en cuanto al presente y problemática en cuanto al futuro" (336), en la que "el único resto de milenarismo de la faz anterior tal vez sea la confianza con que se admite que la remoción del imperialismo traerá, por sí misma, la explosión del progreso" (336).

Pero el fin del imperialismo no es, para Candido, cosa tan sencilla, y no es fácil precisamente porque "la dependencia cultural [es un] hecho considerado natural — dada

\footnotetext{
${ }^{5}$ Mi propuesta de que Antonio Candido, con su privilegio de la alta tradición literariay relativo desinterés por la cultura popular, y Jorge Luis Borges, cuyas simpatías conservadoras son bien conocidas, son relevantes para el subalternismo puede producir cierta perplejidad. No me parece sin embargo sustancialmente diferente en espíritu de la que lleva al grupo hindú de Estudios Subalternos a privilegiar el postestructuralismo francés en su propia genealogía.
} 
nuestra situación de pueblos colonizados que o descienden del colonizador o sufrieron la imposición de su civilización" (342). Por lo tanto habría que asimilar una molesta paradoja: debe rechazarse el imperialismo en el orden político y en el orden económico, pero el imperialismo en el orden cultural debe, por el contrario, abrazarse con cierto entusiasmo precavido, puesto que sólo la apropiación radical de formas culturales eurocéntricas podría hacer posible que la dependencia evolucionara hacia la no-dependencia. Candido vislumbra la paradoja sobre la que construye su pensamiento (al mismo tiempo rechazar y asumir el imperialismo, por más que desde distintos órdenes de experiencia) pero sólo, en mi opinión, para negar su calidad de paradoja y naturalizarla como algo perfectamente lógico:

[C]uanto más se entera de la realidad trágica del subdesarrollo, más el hombre libre que piensa se deja penetrar por la inspiración revolucionaria, es decir, cree en la necesidad del rechazo del yugo económico del imperialismo, y de la modificación de las estructuras internas, que alimentan la situación de subdesarrollo. Sin embargo, mira con más objetividad el problema de las influencias, considerándolas como vinculación cultural y social. (347)

Así, por ejemplo, la apropiación latinoamericana de las formas de la novela europea no debería ser entendida como "imitación" o "reproducción mecánica" sino más bien como "participación de los recursos que vienen a ser bien común a través de la situación de dependencia, contribuyendo así a hacer de ésta una interdependencia" (348).

Candido está pensando, por supuesto, en los grandes logros formales de la novela latinoamericana del boom, que en 1970 están ya empezando a consumar, al menos según todas las apariencias, un contramovimiento a la dependencia cultural, cuya más obvia prueba sería el hecho de que esas novelas eran ya entonces parte de los circuitos internacionales de consumo cultural. Y sin embargo por algo esas novelas seguían siendo novelas latinoamericanas. De hecho, en la explicación de Candido, empezamos a entender cómo su percepción de la historia de la novela latinoamericana incluye una clara teleología cuyo resultado final anticipa prolépticamente lo que antes llamé la situación fundacional del subalternismo: esto es, la vacilación constitutiva entre afirmación de singularidad cultural y su abandono como ilusión ideológica. Esta similaridad estructural, de ninguna forma, por supuesto, libre de complicaciones políticas, es, entre otras, lo que me lleva a pensar que debería hablarse de un retrazamiento de fronteras epistémicas más que de un cambio paradigmático radical en el modelo subalternista.

Candido distingue tres fases en la historia de la novela latinoamericana moderna, coincidentes en grueso con sus tres fases de conciencia cultural. En primer lugar reconoce un "regionalismo pinturesco" que corresponde a la fase eufórica de nativismo de nuevo país (gauchismo, sertanejismo, Rivera, Gallegos). En segundo lugar, identifica un "regionalismo problemático" (la novela social, el indigenismo, la novela del nordeste brasileño, etc.). Y hay una tercera fase

que se podría llamar superregionalista. Ella corresponde a la conciencia lacerada del subdesarrollo y opera una superación del tipo de naturalismo que se basaba en la referencia a una visión empírica del mundo; naturalismo que fue una tendencia estética peculiar a una época, en la cual triunfaba la mentalidad burguesa y correspondía a la consolidación de nuestras literaturas. (353) 
El superregionalismo constituye para Candido "una especie nueva de literatura que todavía se articula de manera transfiguradora con el propio material del nativismo" (353). Es por lo tanto al mismo tiempo nuevo y anclado en las más rancias tradiciones de la cultura latinoamericana criolla, entendida, por cierto generosamente, en su sentido integracionista e inclusivo.

Me parece obvio que el énfasis regionalista, presente en las tres fases de la historia de la novela según Candido, no es sino el énfasis en la singularidad cultural latinoamericana, y así debe entenderse como la defensa latinoamericana contra la absoluta absorción en paradigmas culturales eurocéntricos. En otras palabras, el énfasis regionalista es el elemento sin el cual la dependencia nunca podría aspirar a su propia metamorfosis en la llamada interdependencia. Ahora bien, al mismo tiempo que esta historia de la novela enfatiza la singularidad regionalista, desarrolla también un contramovimiento a lo largo de sus tres fases que sólo encontrará su apoteosis en la tercera de ellas. En el superregionalismo, podría decirse, la singularidad latinoamericana "cambia de piel", para usar el título de la novela de Carlos Fuentes quizás más fuertemente implicada en esta aventura, y abandona la particularidad regional en cuanto tal para lograr lo que Candido llama "la universalidad de la región" (353). También podría decirse de este segundo elemento o contramovimiento que es en él, de manera diferente y complementaria a como ocurre en el énfasis regionalista, donde el lugar mismo de la dependencia latinoamericana queda transfigurado como lugar de interdependencia universal.

En la historia de Candido, y no hay que olvidar su influencia masiva sobre toda una generación de críticos, la singularidad regional es por un lado saludada y vindicada como subversiva o resistente dentro del mismo aparato literario que la representa; y es a la vez subalternizada por el aparato literario mismo, que no puede no proceder a su apropiación y borramiento tendencial desde la supuesta perspectiva del logro de una universalidad teórica. Ahora bien, el subalternismo procede de manera similar en relación con el sujeto subalterno.

El superregionalismo comparte, por lo tanto, algunos elementos estructurales importantes con los estudios subalternos. Habría que mencionar otro: igual que la novela superregionalista "opera una superación del tipo de naturalismo que se basaba en la referencia a una visión empírica del mundo" (353), de la misma manera los estudios subalternos abjuran del empirismo positivista y abrazan, en sus propios términos, una práctica de lo espectral. Si el empirismo/naturalismo lo tenía todo en común con la consolidación de la hegemonía burguesa, los estudios subalternos no son nada excepto práctica contrahegemónica. Como dice el "Founding Statement," lo subalterno es "por definición no registrado o registrable como sujeto histórico capaz de acción hegemónica" (136). Por lo tanto el sujeto subalterno no es nunca objeto de investigación empírica sino que debe localizarse, espectralmente, "en los dobladillos de las epistemologías y prácticas administrativas y socioculturales previamente articuladas, en el 'cloning' de las mentalidades culturales, y en los pactos sociales contingentes que ocurren en todas las coyunturas transicionales" (144). En otras palabras, el sujeto subalterno es precisamente un sujeto contraempírico, "el sujeto efectivo, indestructible e inevitable que nos prueba [siempre de antemano] equivocados" (146). Y esta parece ser su única posible definición. 
Sin duda hay algo ligeramente desconcertante y quizás no enteramente bienvenido en estas similaridades estructurales entre los proyectos superregionalista y subalternista. Al fin y al cabo, superregionalismo es meramente otro nombre para la empresa cultural obviamente hegemónica llamada "novela del boom," que organiza, y al mismo tiempo responde, al paradigma dominante en la interpretación de la cultura latinoamericana durante los años setenta e incluso los ochenta. El subalternismo nace en oposición activa y consciente frente a él, como forma de cuestionar "los paradigmas maestros usados en la representación de sociedades coloniales y postcoloniales en las prácticas culturales hegemónicas desarrolladas por grupos de élite y en los discursos disciplinarios de las humanidades y las ciencias sociales que tratan de representar el funcionamiento de esas sociedades" (“Founding" 136).

¿Dónde está, pues, la diferencia o la discontinuidad? Para encontrarla, quizás debiéramos dirigirnos a lo que antes quedó detectado como una paradoja no tanto irresuelta como incluso no reconocida en la formulación de Candido. Para Candido la lucha contra el imperialismo en las esferas política y económica era una consecuencia natural de la conciencia del subdesarrollo. Sin embargo, el imperialismo en la esfera cultural creaba una serie de demandas radicalmente distintas para la acción contrahegemónica. Candido llega a decir que el nativismo, llevado a un extremo, en la medida en que cuestionaría "el uso de formas importadas" tales como "el soneto, el cuento realista, y el verso libre asociativo" (345), es "siempre ridículo", puesto que equivale a "oponerse al uso de los idiomas europeos que hablamos" (345). "En los estratos profundos de la creación", dice Candido, la dependencia cultural "deja de serlo para transformarse en forma de participación y contribución a un universo cultural a que pertenecemos, que rebasa las naciones y los continentes, permitiendo la reversibilidad de las experiencias, la circulación de los valores" (345). Por eso, para él, el problema de las influencias culturales debe confrontarse "con más objetividad, ... considerándolas como vinculación cultural y social" (347).

En mi opinión esta afirmada "normalidad" o "naturalidad" de la dependencia cultural se convierte en el asunto decisivo y en la piedra de toque contra la que el subalternismo latinoamericano puede y debe organizar su deseo de oponerse a paradigmas previamente articulados. En otras palabras, la "naturalidad" de la dependencia cultural y de su corolario la supuesta "interdependencia" es el paradigma contra el que reaccionan los estudios subalternos. Además: la fuerza histórica de tal reacción subalternista depende del fallo del paradigma previo, no del voluntarismo subalternista. Sólo cuando el superregionalismo triunfa en sus esfuerzos de integración cultural se hace inmediatamente percibible que la integración superregionalista es meramente autointegración - y se hace obvio hasta qué punto esa integración es excluyente de tantas formaciones culturales subalternas en Latinoamérica.

Es decir, con el superregionalismo sólo el segmento superregionalista de la cultura y de la sociedad latinoamericana logra lo que Candido llama interdependencia. La tautología, aquí, muerde. El triunfo superregionalista simultáneamente revela su más profundo fallo o incapacidad de operar la redención cultural de vastos segmentos de la población latinoamericana, para quienes la "interdependencia" de Candido acaba siendo una forma todavía más extrema de dependencia histórica. El elemento "transfigurador" del superregionalismo, su llave de conversión en universalismo en el momento de su integración a los circuitos globales de circulación cultural, fracasa en la transfiguración de lo que motivó 
históricamente su existencia: llámese subdesarrollo latinoamericano, o retraso; llámese diferencia socio-cultural; ollámese subalternidad latinoamericana, que permanece irredenta. Ahora bien, tal fracaso no es un fallo de la voluntad, y no es tampoco en última instancia un fallo cultural. Es más bien, como siempre son estas cosas, un fallo cuyo referente debe localizarse en las esferas políticas y económicas.

El nativismo eufórico es la reacción y expresión cultural de las burguesías latinoamericanas emergentes a lo que Tulio Halperín Donghi llama "el orden neocolonial," incipiente a partir de 1880 en algunos países, algo más tarde en otros, y que sufre una crisis sistémica y final en 1929. Las dos fases caracterizadas por la conciencia del subdesarrollo corresponden a los dos momentos definitorios (antes y después de la Segunda guerra mundial) del estado nacional-popular latinoamericano (podría llamarse también estado fordista-keynesiano, estado de planificación, etc.), cuya construcción es concomitante a la del modelo de desarrollo económico llamado de "industrialización por sustitución de importaciones". Este es un periodo histórico en el que las formaciones estatales latinoamericanas deben implementar una estrategia estatalista de desarrollo: dura aproximadamente cinco décadas y viene a terminar durante la crisis de la deuda de 1982. En palabras de Gary Gereffi y Lynn Hempel,

En los setenta, la fuente principal de financiamento externo para ISI [industrialización por sustitución de importaciones] cambió de la inversión extranjera directa a préstamos cada vez más onerosos de capital extranjero, que culminaron en la crisis de la deuda de 1982. A los ochenta se les llamó "la década perdida" en muchas naciones latinoamericanas, que sufrieron recesión económica, inflación en espiral, severos cortes presupuestarios en gastos sociales, altos niveles de desempleo, y pobreza ubicua. (20)

La crisis de 1982 resultó en el desmantelamiento del estado de planificación nacionalpopular y en la institucionalización de políticas neoliberales a un costo social muy alto. ${ }^{6} \mathrm{La}$ transición de la década de los ochenta desde sustitución de importaciones hacia estrategias de desarrollo orientadas a la exportación marca el inicio de un periodo, el presente, en el que las economías latinoamericanas han experimentado un avance drástico hacia la globalización, entendida como la parcial "integración funcional entre actividades internacionalmente dispersas" (19), y donde "las corporaciones transnacionales son los actores fundamentales" (27). La dependencia latinoamericana respecto de las corporaciones transnacionales se ha incrementado exponencialmente a lo largo de los últimos quince años, a la vez que el estado latinoamericano, malamente dañado en su independencia y capacidad de acción autónoma, se ha manifestado incapaz de obtener concesiones sociales y económicas de esas mismas corporaciones que han absorbido buena parte de su poder. Como resultado, un desarrollo o subdesarrollo todavía más desigual que el que motivaba la conciencia catastrófica a la que

\footnotetext{
"Ver Carlos Vilas, "Neoliberal Social Policy", para un recuento conciso de los costes específicos de la política neoliberal en las capas subalternas latinoamericanas. También sobre las diferencias entre el estado latinoamericano nacional-popular o keynesiano-fordista y el estado neoliberal. Información más detallada sobre el impacto del neoliberalismo en Latinoamérica en Victor Bulmer-Thomas ed., New Economic Model.
} 
se refiere Candido se ha hecho endémico en la región. En la formulación excesivamente prudente de Gereffi y Hempel, "para la mayoría de la región - trabajadores en puestos de baja cualificación y bajo salario, campesinos en economías de subsistencia o de sectores dedicados a exportaciones tradicionales, consumidores afectados por devaluaciones y standards erosionados de vida, y compañías incapaces de competir en mercados más y más abiertos - los costos de la globalización parecerían exceder sus beneficios" (27).

El viejo sueño de interdependencia - mediante la internacionalización de vínculos económicos basados en un desarrollo sostenido y en paralelo con la integración cultural de la producción simbólica latinoamericana y sus equivalentes metropolitanos - se terminó. La caída del estado nacional-popular ha dado lugar a nuevos movimientos sociales de carácter centrífugo que ya no están primariamente interesados en su integración nacional, como alguna vez lo estuvieron. El superregionalismo se acaba cuando las condiciones que presidieron su ascenso ideológico - la posibilidad de una integración nacional a la economía global adecuada y exitosa, razonablemente igualitaria, y dirigida por una burguesía nacional criolla y occidentalista - dejan de estar presentes. El subalternismo latinoamericano es en última instancia una consecuencia del sueño fallido de la modernización nacional integrada. Y es una respuesta al agotamiento del superregionalismo, cuyos procedimientos estéticos aparecen ya hoy como singularmente ineficaces para adecuarse al estado fragmentado de las sociedades latinoamericanas - en la ausencia de narrativas maestras de redención nacional.

He estado tratando de contribuir a la arqueología parcial del subalternismo latinoamericano como empresa crítica. He tratado de establecer que la característica fundacional del subalternismo es también compartida, en otra versión, por el superregionalismo, entendido como paradigma predecesor dominante de interpretación. Que hay una diferencia entre subalternismo y superregionalismo es obvio, y también ha sido (muy parcialmente) estudiada. Esa diferencia fue referida a la historia económica y social. Pero falta por esbozarse una caracterización positiva del subalternismo mismo, más allá de su estatuto como práctica crítica antisuperregionalista, contraempírica, y contrahegemónica.

La distancia histórica, cuando es presentada como distancia, no es nunca simplemente histórica. Si el subalternismo puede llegar a ofrecerse como una expansión y retraso de bordes epistemológicos, y si tiene la posibilidad de convertirse en un paradigma crítico alternativo, más allá del nativismo y de sus avatares y conversiones, debe incorporar explícitamente una rearticulación propiamente teórica de su relación al paradigma previo. Tal rearticulación teórica debe incluir el recuento de cómo el subalternismo ha de releer la secuencia histórica que quiere sustituir o suplementar.

Desde fines del siglo pasado el regionalismo ha venido constituyendo un modelo cultural dotado de privilegio epistemológico para la interpretación de la historia latinoamericana. Pero, como ideología dominante para la autointerpretación latinoamericana, el regionalismo, en particular en su último avatar como superregionalismo, ha sufrido una crisis extrema a manos del orden neoliberal, de la que puede no recuperarse ya. La pregunta entonces es: ¿quién o qué puede hoy fundamentar una vindicación de privilegio epistemológico? ¿Desde qué posición geocultural es posible desarrollar un pensamiento crítico re-formulado? ¿Desde la perspectiva misma de la globalización? ¿O desde la perspectiva contraria de la localidad globalizada? Obviamente, el subalternismo aspira a 
contestar esas preguntas en toda su amplitud, y conviene entenderlo en un sentido fuerte como movimiento antiintegracionista y anticriollista. ¿Cuál es su positividad específica?

El "Founding Statement" del Grupo de Estudios Subalternos Latinoamericanos dice en cierto lugar: "Las formas de alta cultura como la literatura han sido suspendidas por las críticas desarrolladas por la deconstrucción, el feminismo, y los estudios afroamericanos y chicanos en Estados Unidos, y en su lugar un sentido antropológico de la cultura como 'experiencia vivida' viene a imponerse" (140). Esta "experiencia vivida", de invocación algo mágica, a la que ya me referí - ¿incorpora quizá algún tipo de transparencia radical a la que el subalternismo tendría acceso listo e inmediato? ¿O es más bien, precisamente, el lugar secreto del diferimiento y posposición de una articulación teórica que amenaza también con posponer indefinidamente las posibilidades subalternistas de ofrecerse como una forma eficaz de cultura crítica en el Nuevo orden mundial? Quizás la "experiencia vivida" es la cifra contraintencional y la imagen especulativa de lo que en el superregionalismo acabó por mostrarse incapaz de dar cuenta de sus exclusiones.

La tercera y última parte de este trabajo, que es una lectura de "La lotería en Babilonia," de Jorge Luis Borges, trata de rastrear en el pensamiento textual del maestro argentino elementos posibles para la rearticulación teórica de la empresa crítica en la época neoliberal. Si bien no se trata de pretender una lectura de Borges como subalternista avant la lettre, el subalternismo puede beneficiarse de la respuesta que ofrece "La lotería en Babilonia" al problema esencial que es la pregunta por el fundamento crítico de la acción opositora en tiempos en los que el superregionalismo está ya transmutado en un régimen sociocultural de control global —en el que la diferencia subalterna ha venido a ser quizá la última esperanza de lo que antes solía llamarse libertad.

\section{DesnarRativización DEl APARATO DE ESTADO Y RETORNO DE LA HISTORIA}

Supuesto el lugar central de Jorge Luis Borges en el canon posmodernista, al tratar de entenderlo desde o para nuestro propio tiempo uno nunca sabe si la forma adecuada de lectura es histórica u ontológica. En relación con Borges, sin embargo, al menos con el Borges de Ficciones y El Aleph, la lectura meramente ontologizante es tan reductiva como cualquier lectura meramente histórica. La oscilación entre historia y ontología es una condición de posibilidad para la lectura de Borges, que debería ser considerado un pensador de conciencia situacional para quien el pasaje a la teoría es siempre de antemano determinante; o un pensador teórico para el que el conocimiento histórico es meta final. En la vieja formulación lukacsiana, en Borges la "ciencia" se hace "conciencia" y la "conciencia" se hace "ciencia" —entendiendo "ciencia" ontológicamente y "conciencia" históricamente. Los intérpretes no deberían reificar el pensamiento de Borges en ninguno de los dos polos, ni entender cualquiera de los polos de forma reificada. ${ }^{7}$

\footnotetext{
${ }^{7}$ Tomo la expresión "conciencia situacional" de Jameson, "Third World" 85. En "Postmodernism and the Market" Jameson se refiere explícitamente a las connotaciones sartrianas del término: "El concepto sartreano de situación es una manera nueva de pensar la historia como tal" (288). En otro pasaje se refiere a conciencia situacional como "un encuentro desmistificador, pupila a pupila, con la vida diaria, sin distancia y sin embellecimientos" (286).
} 
Quiero leer "La lotería en Babilonia" (1941) como reacción a la formación estatal que se había venido desarrollando en Occidente, y por consiguiente en Argentina, durante los años treinta, y como anticipación de la evolución de tal formación estatal hacia su configuración presente. En otras palabras, creo que "La lotería en Babilonia" ofrece a la vez una lectura sintomática de la constitución del estado keynesiano, el estado planificador, o el estado intervencionista, y también una anticipación o prognosis catastrofista de lo que sería la consecuencia histórica del estado keynesiano, es decir, lo que Gilles Deleuze llama la Sociedad de control, para la que la más frecuente expresión alternativa "estado neoliberal" es obviamente designación equivocada o excesivamente ambigua. Borges aparece entonces como pensador precursor de lo que Antonio Negri y Michael Hardt llaman, haciendo uso de la economía política de Marx, "la subsunción real de la sociedad bajo el capital" (14). Podría hacerse una lectura semejante de "Tlön, Uqbar, Orbis Tertius", e incluso de "La biblioteca de Babel". Pero si es cierto que Borges anticipa en su trabajo textual la evolución de las formas sociales, el análisis crítico no debería parar en el punto de descubrimiento de sus poderes proféticos, sino que debería avanzar más allá hasta cuestionar la forma particular en la que su trabajo no es simplemente descriptivo, sino que es crítico, esto es, histórico en el sentido propio.

Desde el punto de vista que tendré entonces que llamar, imagino, impropiamente histórico, voy a limitarme a proponer que en "La lotería en Babilonia" Borges interpreta el estado keynesiano, que en Latinoamérica como en otros lugares es resultado directo del jueves negro de 1929. Como dice Halperín Donghi, “[después de 1929] los estados nacionales fueron ... las únicas entidades económicas capaces de navegar tan altos mares ... y los estados latinoamericanos empezaron a ejercer funciones y a adoptar técnicas inimaginables tan sólo unos años antes ... La multiplicación de funciones estatales señalizó un abandono total de los principios de laissez-faire que habían guiado la política económica neocolonial. La conciencia de la emergencia de la situación estaba tan extendida que ... nadie disputó la expansión del poder estatal per se" (209-10). La formación estatal que comenzó su nueva vida tras 1929 es el estado planificador, cuya fase más aguda en Argentina fue el estado nacional-popular peronista, y que sólo encontraría su fin durante la crisis de la deuda de 1982.

Desde el punto de vista ontológico o teórico mantendré que Borges, en su relato, radicaliza el entendimiento de los fenómenos históricos hacia una prolepsis de lo que, para él, era lo post-contemporáneo: el pasaje del estado intervencionista hacia el estado de control como verdad teleológica del estado moderno. Su manifestación contemporánea en Latinoamérica, eufemísticamente llamada "neoliberal", ha significado entre otras cosas, como veíamos, un avance drásticamente acelerado hacia la globalización, mediante la que la dependencia latinoamericana de las corporaciones transnacionales se incrementa exponencialmente. En tiempos de capitalismo tardío, los estados latinoamericanos se hacen subsidiarios de un aparato estatal transnacional quizás inexistente pero no por ello menos eficaz, cuya función es meramente la de asegurar la reproducción incesante de la capacidad productiva en y para la "integración funcional de actividades internacionalmente dispersas" (Gereffi-Hempel 19). El espectral estado transnacional de acumulación flexible reemplaza el estado nacional-popular y sus viejas legitimidades. Lo que queda es un nuevo régimen social de "metastabilidad perpetua" (Deleuze 4) basado en el mercado como mecanismo último de control. Parto aquí de la hipótesis primaria de que la noción borgesiana de la lotería 
en su última fase, allí donde debe enfrentar el límite y la posibilidad de su propia inexistencia (allí donde la lotería ha dejado de importar, puesto que sus efectos son ya plenamente universales), es una alegoría de la metástasis social perpetua (lo que los teóricos neoliberales llaman simplemente "el mercado") como régimen de control social total. Pero mi pregunta real va más allá de la descripción para tratar de entender, a través de la descripción, la modalidad borgesiana de crítica histórica.

"La lotería en Babilonia" es el relato que nos da un oscuro narrador (que resulta estar temporalmente fuera de Babilonia) de una institución estatal altamente peculiar y de su historia: la lotería, en su avatar babilónico. El narrador nos dice pronto en el cuento que en Babilonia "la lotería es una parte principal de la realidad" (442). Cómo ha llegado a ser parte tan principal de lo real es su tema - un tema, por cierto, del que la lógica del relato nos hace creer que le ha sido dado por el sistema de lotería mismo, como una sanción más del azar del juego. En Babilonia la lotería se desarrolla históricamente desde ser un juego patrocinado en su origen por una corporación privada - el narrador la llama "la Compañía" (442) - hasta ser la forma misma de la total administración de la experiencia por parte de la "tenebrosa corporación" (447). Si en el origen la lotería es una institución de la sociedad civil dependiente de mecanismos de mercado, hacia el final la noción misma de sociedad civil se ha hecho imposible e insostenible, puesto que la lotería se ha fusionado con la vida hasta tal punto que ambas son experiencialmente indistinguibles. En ese momento, el presente de la narración, los resultados de la lotería parecen afectar y determinar todas y cada una de las facetas de los acontecimientos humanos e incluso cósmicos. La lotería, al final de su evolución, se ha hecho tal "parte principal de la realidad" que es de hecho el mecanismo primario de lo real.

Hacia el final de la historia el narrador insinúa que no se puede decidir si la lotería debiera considerarse mecanismo primario de lo real o, al revés, si la lotería es ya lo real como mecanismo primario: "es indiferente afirmar o negar la realidad de la tenebrosa corporación, porque Babilonia no es otra cosa que un infinito juego de azares" (447). Dado que la escritura misma del relato puede ser (o puede no ser) resultado de la lotería misma, la verdad de tal afirmación queda infinitamente suspendida - aunque la afirmación misma suspenda infinitamente la verdad, es tal suspenso mismo lo suspendido, en doble indecidibilidad. El lector debe entonces hacer preliminarmente un juicio ideológico, confrontado con al menos tres opciones: 1) la lotería existe, y el narrador es su inadvertido servidor; 2) la lotería ya no existe, pero el narrador es incapaz de decidir sobre su inexistencia; 3) la lotería existe, y el narrador nos confunde intencionadamente. La opción real para el lector no es sin embargo decidirse por una de esas tres opciones, o sus negaciones respectivas, sino que entra en un orden de decisión alternativo que la primera (y falsa) opción a un tiempo preludia e introduce: si la verdad del aserto del narrador ha quedado indefinidamente pospuesta por cuanto no puede ser nunca comprobada, el lector debe decidir permanecer en el perpetuo enredo, atrapado en la perplejidad literaria, o desenredarse rehusando aceptar el dilema en cuanto tal. La última opción requiere, como es frecuente en Borges, un complicado acto de análisis metacrítico en el que se juega la perspectiva teórica general del relato.

Cuando la presión del pueblo pidiendo igualdad logra la imposición de "un orden nuevo" en la historia de Babilonia, la Compañía acepta "la suma del poder público" y se hace estado (443): 
El justo anhelo de que todos, pobres y ricos, participasen por igual en la lotería, inspiró una indignada agitación cuya memoria no han desdibujado los años. Algunos obstinados no comprendieron (o simularon no comprender) que se trataba de un orden nuevo, de una etapa histórica necesaria. ... Hubo disturbios, hubo efusiones lamentables de sangre; pero la gente babilónica impuso finalmente su voluntad, contra la oposición de los ricos. El pueblo consiguió con plenitud sus fines generosos.

El "orden nuevo", el triunfo populista entendido como integración nacional-popular, es por lo tanto el remoto comienzo de la Sociedad de control. El estado, que no es en principio sino la corporación que administra la lotería, mantiene su extraordinaria expansión -necesaria para que la lotería funcione siempre más suave y consistentemente- hasta que llega el momento en el que cada acto humano ocurre en función y como función del poder estatal. El narrador afirma entonces que la subsunción real y total de la vida en la formación estatal ha sido lograda, quizás para poder afirmar a continuación que tal logro marca también el punto en que la forma estatal queda subsumida en la realidad total de la vida. Ha tenido lugar una inversión dialéctica: el estado planificador se ha metamorfoseado en su propio espectro para mejor saturar así el campo de lo real, que es ahora equivalente, en virtud de la inversión dialéctica misma, al campo de lo espectral. La anticipación proléptica queda de este modo consumada en el texto de Borges: la sociedad de control, que es nuestro presente, está prometida en el texto de 1941 como consecuencia teleológica del desarrollo del aparato de estado a partir de su expansión nacional-popular.

Se hace necesaria una objeción crítica, pero debería entenderse que es una objeción crítica posibilitada por el cuento mismo. La distancia irónica de Borges, o la postulada "indiferencia" del narrador, no esconden sino que revelan la diferencia omnideterminante: el pasaje de una lotería intervencionista hacia una lotería total es también el pasaje hacia una dominación total de lo humano; y es, epistemológicamente, el pasaje de la conciencia histórica hacia su reificación en ontología. "Afirmar o negar la realidad de la tenebrosa corporación" es precisamente lo que no es indiferente, puesto que es lo que abre la posibilidad misma de diferencia. "Afirmar" significa optar por la historia, y mantener abierta la distinción entre conocimiento y conciencia de experiencia; "negar" significa optar por la reificación de la historia, y colapsar conocimiento y experiencia.

Concedido que "Babilonia no es otra cosa que un infinito juego de azares," todo depende ya de decidir que tal "juego de azares" sigue un destino causado por una determinación en última instancia humana, puesto que está orquestado por la formación estatal como lugar del poder, o que tal determinación humana es o se ha hecho irremisiblemente naturaleza, y en cuanto tal no puede ser ya imaginada alternativamente. La noción misma de libertad histórica está en juego en la decisión metacrítica que el narrador nos ofrece paradójicamente al postular que no hay decisión por hacer, o que la decisión es "indiferente".

Lo que está en juego, en otras palabras, es la posibilidad teórica de un "afuera" de la ideología o, como lo formularía Louis Althusser en su autobiografía, "cómo escaparse del círculo permaneciendo dentro de él" (Future 319); en los términos del relato, "cómo escapar a la lotería permaneciendo dentro de ella" o, si se quiere, cómo escapar al estado de control permaneciendo dentro de él. La conciencia propiamente histórico-crítica del cuento de Borges depende de la forma o formas posibles de resolución de tal pregunta que el texto ampara. 
Sólo la posibilidad teórica de un escape puede dejar abierta la posibilidad de cambio histórico y la destrucción final de lo que quizá ya vamos entendiendo, a través de esta lectura, como el modo de producción tardo-capitalista bajo la alegoría de la total lotería estatal, que para Borges no era sino, en 1941, una posibilidad futura. Si la lotería existe, entonces, entenderla como contingente y no necesaria es lo fundamental. Pero incluso si la lotería estatal no existe ya, no importa ese hecho sino sólo darse cuenta de que tal es el caso. En la formulación clásica de Althusser: "ese es el conocimiento que tenemos que alcanzar, si se quiere, mientras hablamos dentro de la ideología, y desde la ideología tenemos que trazar un discurso que intente romper con la ideología, para osar ser el principio de un discurso científico (esto es, sin sujeto) sobre la ideología" ("Ideology" 173).

A propósito, puede uno preguntarse si o cómo habría modificado Althusser su noción de ideología y del aparato ideológico del estado si hubiera leído y meditado seriamente sobre "La lotería en Babilonia". Pero quizás lo hizo, y lo hizo hasta un grado inmedible. Nunca lo sabremos, aunque eso no debería ser óbice para postular que "La lotería en Babilonia" es una de las fuentes teóricas o de los recursos anticipativos de la noción althusseriana de ideología. Por eso conviene registrar que el texto de Borges incluye una referencia siniestra a Althusser que Borges no podía saber que era una referencia a Althusser. Quizás, por lo tanto, fue Althusser quien retrospectivamente la hizo referencia a sí mismo. Hacia el final del cuento el narrador pregunta: "el soñador que se despierta de golpe y ahoga con las manos a la mujer que duerme a su lado, ¿no [ejecuta], acaso, una secreta decisión de la Compañía?” (446).

Como se sabe, el domingo 16 de noviembre de 1980, por la mañana, Althusser se descubrió a sí mismo en la posición de ese soñador borgesiano. En palabras de Althusser:

Emergí tras una noche profunda que no he sido nunca capaz de medir y me encontré al pie de mi cama, en bata, con Hélene extendida frente a mí, y yo masajeando su cuello y sintiendo un intenso dolor en mis antebrazos, sin duda a causa del masaje. Entonces me di cuenta, sin saber por qué, excepto por sus ojos inmóviles y la punta lastimosa de su lengua entre sus dientes y labios, que estaba muerta. (Future 253-54)

Enigmáticamente la propia teorización althusseriana del discurso del inconsciente como discurso del "Orden del significante humano" ("Freud and Lacan" 213) se relaciona con su propia inscripción en un texto borgesiano que es también un texto sobre el Otro como significante absoluto. El narrador de "La lotería en Babilonia" compara los trabajos de la Compañía a los trabajos de Dios ("ese funcionamiento silencioso, comparable al de Dios" [446]), igual que para Althusser "el interpelamiento de los individuos como sujetos presupone la "existencia' de un Sujeto Otro central y Unico" (“Ideology" 178): Dios o la corporación, Dios o el Estado. Pero cierro la aparente digresión.

La posición del narrador en "La lotería en Babilonia" es objetivamente constitutiva de ideología en términos althusserianos. La ideología es para Althusser una condición necesaria de lo que él llama la "reproducción de las fuerzas productivas". En efecto, sea que la lotería exista real o espectralmente, la misión del narrador es total y absolutamente ideológica. Podría ser un servidor inadvertido de la compañía, en posición por lo tanto de trabajador, o un colaborador avisado, y así un agente de explotación. De cualquier manera, sirve los mismos intereses: 
la reproducción de las fuerzas productivas requiere ... la reproducción de su sumisión a las reglas del orden establecido, esto es, la reproducción de la sumisión a la ideología dominante para los trabajadores, y la reproducción de la capacidad de manipular la ideología dominante correctamente para los agentes de la explotación y la represión, de modo que estos últimos también colaboren "con palabras" a la dominación de la clase dirigente. ("Ideology" 132-33)

Las frases finales del relato ("Es indiferente afirmar o negar la realidad de la tenebrosa corporación ...") parecerían a primera vista simplemente servir a las estrategias de reproducción de las fuerzas de trabajo, en otras palabras, a la perpetuación del poder del estado en la preservación de la hegemonía social del sistema de lotería. Así el soñador siempre ahogará a su mujer, después de todo. Pero algo más viene también a ser dicho.

Como acto textual total, ¿es "La lotería en Babilonia" una contribución más a la reproducción de las fuerzas de trabajo en el sentido althusseriano, es decir, por apoyarla ideológicamente al fomentar o la sumisión a la lotería o su naturalización como equivalente a la vida misma ("Babilonia no es otra cosa que un infinito juego de azares")? ¿O es más bien, por el contrario, un forma de apertura al proceso sin sujeto de la historia, al afuera del interpelamiento por el aparato de la lotería, a la ruptura del Orden del significante?

$\mathrm{El}$ narrador de "La lotería en Babilonia" nos cuenta una historia monstruosa, porque alcanza a todas las historias posibles al mismo tiempo que las mata a todas, vaciándolas de autonomía: si la lotería manda y determina cualquier acaecer humano, todas las historias son simplemente esa historia. La administración total de la vida mediante una lotería infinita e incesante implica que la vida se halla totalmente desnarrativizada, puesto que responde en cada uno de sus momentos a una orden que emana de arriba. Desde la perspectiva de la lotería total, la vida es siempre de antemano heterónoma, "no otra cosa que un infinito juego de azares". 8

Paradójica pero inevitablemente, sin embargo, tan total desnarrativización de la existencia como apoteosis de la ideología nos devuelve a una posibilidad alternativa de entendimiento. La clausura final del relato, esto es, la lograda alegorización de la totalidad social como siempre de antemano alienada, siempre de antemano desapropiada, "redirige", en palabras que Jameson aplica a otro contexto, "nuestra atención a la historia misma y a la variedad de situaciones alternativas que ofrece" ("Postmodernism" 288). Ciertamente no hay, en el texto de Borges, afirmación alguna de autonomía humana: sólo hay, en la dimensión metacrítica del texto, algo así como una burla o un solapado cuestionamiento del principio de heteronomía radical - y eso es, hasta cierto punto, también una afirmación (¿no-humanista?) del potencial humano de libertad.

"Los ignorantes suponen que infinitos sorteos requieren un tiempo infinito; en realidad basta que el tiempo sea infinitamente subdivisible, como lo enseña la famosa parábola del Certamen con la Tortuga" (445). En otro texto sobre la paradoja griega Borges dice: "Nosotros (la indivisa divinidad que opera en nosotros) hemos soñado el mundo. Lo hemos soñado

\footnotetext{
${ }^{8} \mathrm{La}$ insistencia final de Althusser sobre la desnarrativización resulta interesante en este contexto: "mi objetivo: nunca contarme a mí mismo historias, que es la única definición de materialismo que he suscrito nunca" (Future 169); “"No caer en contarme cuentos' todavía permanece para mí como sola y única definición del materialismo" (Future 221).
} 
resistente, misterioso, visible, ubicuo en el espacio y firme en el tiempo; pero hemos consentido en su arquitectura tenues y eternos intersticios de sinrazón para saber que es falso" ("Avatares" 204). Tales falsedades destruyen la ontología. En la destrucción de la ontología la historia retorna, y con ella la conciencia histórica.

¿Sería esa conciencia histórica fundamentalmente desnarrativizada - algo así como la radicalización del pensar genuino de Schwarz en lo que Jameson llama "conciencia situacional", esto es, "un encuentro desmistificador, pupila a pupila, con la vida diaria, sin distancia y sin embellecimientos" (Jameson, "Postmodernism" 286) - traducible en los términos subalternistas de "experiencia vivida"? La "experiencia vivida", interpretada, en palabras de Gyan Prakash, "posnacional" y "posfundacionalmente", es decir, como no subsumible o como particularmente resistente a cualquier forma de narrativización heterónoma de la existencia, nos devuelve de lleno a la identificación entre política y dinámica libidinal que es condición del subalternismo como privilegio epistemológico. ${ }^{9}$

La viabilidad misma del subalternismo como nuevo paradigma de pensamiento latinoamericano depende de su capacidad de sostener la negatividad del sujeto subalterno -entendido pues, en su mera diferencia con el sujeto dominante, como conciencia diferencial-mientras a la vez eluda la tentación de no buscar el entendimiento de la totalidad social, circunscribiéndose a una mera política de identidades. Si puede haberse entendido que Antonio Candido está en la genealogía latinoamericana del pensar de la negatividad, por su insistencia en la hipóstasis prouniversalista de la singularidad cultural, entonces quizá se haya entendido también que Borges, para quien la desnarrativización de lo singular es la meta precisa de todas y cada una de las historias, contribuye a la otra genealogía necesaria: la del pensar de la contradictoria totalidad de lo que hay como único fundamento de la historia.

\section{OBRAS CITADAS}

Althusser, Louis. "Freud and Lacan". Lenin and Philosophy and Other Essays. Trad. Ben Brewster. Nueva York: Monthly Review Press, 1971. 189-219.

The Future Lasts Forever. A Memoir. Trad. Richard Veasey. Nueva York: New Press, 1993.

"Ideology and the Ideological State Apparatus. (Notes Towards an Investigation.)" Lenin and Philosophy. 127-86.

Beverley, John, José Oviedo y Michael Aronna eds. The Postmodernism Debate in Latin America. Durham: Duke University Press, 1995.

Borges, Jorge Luis. "Avatares de la tortuga". Prosa completa. Vol. 1. Barcelona: Bruguera, 1980. 199-204.

"La lotería en Babilonia". Prosa. Vol. 1. 441-47.

Bulmer-Thomas, Victor ed. The New Economic Model in Latin American and its Impact on Income Distribution and Poverty. New York: St. Martin's Press, 1996.

\footnotetext{
${ }^{9}$ Prakash, "Writing" 394-403 y passim. Ver sin embargo la polémica respecto a esos dos términos en
} O'Hanlon y Washbrook, y la contestación de Prakash. 
Candido, Antonio. "Literatura y subdesarrollo." César Fernández Moreno ed., América Latina en su literatura. México: Siglo XXI, 1972. 335-53.

Deleuze, Gilles. "Postscript on the Societies of Control". October 59 (invierno 1992): 37.

Gereffi, Gary \& Lynn Hempel. "Latin America in the Global Economy: Running Faster to Stay in Place". NACLA Report on the Americas 29.4 (1996): 18-27.

Halperín Donghi, Tulio. The Contemporary History of Latin America. Trad. John Chasteen. Durham: Duke University Press, 1993.

Herlinghaus, Hermann and Monika Walter eds. Posmodernidad en la periferia. Enfoques latinoamericanos de la nueva teoria cultural. Berlín: Langer, 1994.

Jameson, Fredric. "Postmodernism and the Market". Slavoj Zizek ed., Mapping Ideology. Londres: Verso, 1994. 278-95.

"Third World Literature in the Era of Multinational Capitalism". Social Text 15 (otoño 1987): 65-88.

Latin American Subaltern Studies Group. "Founding Statement”. Beverley, Oviedo, Aronna eds., Postmodernism. 135-46.

Negri, Antonio \& Michael Hardt. Labor of Dionysus. A Critique of the State-Form. Minneapolis: University of Minnesota Press, 1994.

O'Hanlon, Rosalind y David Washbrook. "After Orientalism: Culture, Criticism, and Politics in the Third World". Comparative Studies in Society and History 34 (1992): 141-167.

Prakash, Gyan. "Can the 'Subaltern' Ride? A Reply to O'Hanlon and Washbrook". Comparative Studies in Society and History 34 (1992): 168-184.

"Writing Post-Orientalist Histories of the Third World: Perspectives from Indian Historiography". Comparative Studies in Society and History 32 (1990): 383-408.

Schwarz, Roberto. "As idéias fora do lugar". Ao vencedor as batatas. $4^{\text {a }}$ ed. São Paulo: Duas Cidades, 1992. 13-28.

Un mestre na periferia do capitalismo. Machado de Assis. $2^{\mathrm{a}}$ ed. São Paulo: Duas Cidades, 1991.

"Misplaced Ideas. Literature and Society in Late-Nineteenth-Century Brazil". Misplaced Ideas. Essays on Brazilian Culture. Trad. John Gledson. Londres: Verso, 1992. 19-32.

Vilas, Carlos. "Neoliberal Social Policy. Managing Poverty (Somehow)". NACLA Report on the Americas 29.6 (1996): 16-25.

Williams, Gareth. “After Testimonio: Latinamericanism, Orientalism, and Elusive Loss of the Upper Hand". Journal of Latin American Cultural Studies (próxima publicación). "The Fantasies of Cultural Exchange in Latin American Subaltern Studies". Georg Gugelberger ed., The Real Thing. Durham: Duke University Press, [por publicarse]. 
